\title{
Katholischer Kinder- und Jugendbuchpreis 2005 ,
}

Der Katholische Kinder- und Jugendbuchpreis 2005 ist an Jutta Richter für ihr Buch „Hechtsommer" (Carl Hanser Verlag, München-Wien 2004) verliehen worden.

Die Jury unter Vorsitz von Weihbischof Thomas Maria Renz, Rottenburg-Stuttgart, hat das Werk unter 192 Büchern aus 47 Verlagen ausgewählt. Der mit 5000 Euro dotierte Preis wurde 2005 zum sechzehnten Mal verliehen.

\section{Zum Buch:}

"Hechtsommer" erzählt aus der Perspektive des Mädchens Anna vom Zauber eines lichtdurchfluteten Sommers. Anna und die Brüder Lukas und Daniel sind Freunde. Sie leben als Kinder von Gutsangestellten auf dem Grundstücke eines Schlosses. Die unbeschwerten Kindertage werden jäh zerstört, als Gisela, die Mutter der Jungen, an Krebs erkrankt. Der nahende Tod zeichnet sich ab. Daniel ist in seiner Verzweiflung hinund hergerissen. Auf der einen Seite gibt er Gott die Schuld, auf der anderen Seite verneint er dessen Existenz. In seiner Not sucht der Junge einen Ersatz und findet ihn im Hechtgott. Er wird für ihn zum Sinnbild der Krebserkrankung seiner Mutter. Fortan verfolgt er nur ein Ziel: Wenn er es schafft, den Hecht im Schloßteich $z u$ angeln und zu töten, wird seine Mutter wieder gesund. Tatsächlich gelingt es Daniel mit Hilfe von Lukas und Anna, das Tier an den Haken zu bekommen. Doch gleichzeitig mit dem Tod des Hechtes stirbt die Mutter.

Jutta Richters „Hechtsommer“ ist eine bewegende, dank der präzisen, ernsten und dichten Sprache wunderschön erzählte Geschichte. Mit einem Sinn für die leisen Zwischentöne erzählt sie eindringlich von Freundschaft, Treue und Geschwisterliebe, von Traurigkeit und Abschiednehmen und vom Ende der Kindheit. Die Aussagekraft des Buches wird eindrucksvoll unterstützt von sechs ganzseitigen fotorealistischen Illustrationen von Quint Buchholz.

\section{Zur Preisträgerin:}

Jutta Richter, geboren 1955 in Burgsteinfurt/Westfalen, studierte katholische Theologie, Germanistik und Publizistik in Münster. Sie lebt als freie Schriftstellerin auf Schloss Westerwinkel im Münsterland und in Lucca in der Toskana. Für ihre Werke hat sie bereits zahlreiche Auszeichnungen, Preise und Stipendien erhalten, u. a. 2001 den Deutschen 
Jugendliteraturpreis. Für ihr Gesamtwerk wurde sie zuletzt mit dem Hermann Hesse-Stipendium 2004 ausgezeichnet.

Eine Empfehlungsliste der Jury des Katholischen Kinder- und Jugendbuchpreises 2005 mit 14 weiteren Titeln kann bei der Geschäftsstelle im Sekretariat der Deutschen Bischofskonferenz, Kaiserstraße 161, 53113 Bonn, bestellt werden. 